\title{
A novel conceptual framework to identify the mineral laws in Iran: A real-case application of fuzzy TOPSIS method
}

\author{
Mehdi Ghazanfari $^{\mathrm{a}^{*}}$ and Morteza Hashempour ${ }^{\mathrm{b}}$
}

\begin{abstract}
${ }^{a}$ Professor, School of Industrial Engineering, Iran University of Science and Technology, Tehran, Iran ${ }^{b}$ Post-Doctoral Fellow, School of Industrial Engineering, Iran University of Science and Technology, Tehran, Iran

\begin{tabular}{l}
\hline C H R O N I C L E \\
\hline Article history: \\
Received October 28, 2020 \\
Received in revised format: \\
October 29,2020 \\
Accepted November 172020 \\
Available online \\
November 17, 2020 \\
\hline Keywords: \\
Mineral industry \\
Environmental laws \\
Government role \\
Conceptual framework \\
Fuzzy TOPSIS
\end{tabular}

A B S T R A C T process and environmental factors, the enactment of protectionist environmental laws in the extensive attention especially in countries with high mining conceptual framework to identify the key protection laws in Iran by considering the mineral successful laws and regulations in mineral-developed countries such as Australia, Chile, India, abovementioned countries in resolving similar conflicts in Iran's mineral industry. The key protection laws are selected based on their national and international environmental treaties, mining activity, and laws for the abandoned mines. The proposed framework demonstrates that Iran's mineral laws require revision and more transparency to avoid ambiguity and conflict with mineral property laws and governmental rights.
\end{abstract}

\section{Introduction}

Living in a healthy environment is a fundamental human right all around the world (Smith, 2020). Despite the destructive effects of human development activities on the environment, these activities cannot be stopped due to the increasing development of the industry and the existing competitive conditions. Mineral and their impact are one of these activities that directly affect the environment and nature and it has caused problems. These problems depend on various factors such as topography, soil properties, plant growth potential, type of mineral process, etc. Each country has its environmental laws. Environmental approval is usually required to start mineral activities (Song et al., 2020).

Accurate identification of mineral environmental threads is addressed in the field of environmental geology. Environmental protection and sustainable mine development cannot be achieved without coherent and clear legal rules and reasoned laws backed by strong enforcement. Mines' environment, especially restoring the environment of abandoned mines to the natural life cycle, has legally gained particular importance in the last twenty years (Surianto et al., 2020). While paying close attention to this issue, countries such as Australia, Chile, and Canada have tried to improve the environment by changing their laws and regulatory approaches. However, countries like China are exploiting mines regardless of environmental issues. In Iran, the environment is exposed to misuse due to extensive deforestation, discharge of polluted effluents, soil erosion, groundwater pollution, and destruction of natural habitats. Reviewing and patterning the environmental laws of other countries can provide all stakeholders with an opportunity to change legal mechanisms and start moving in the right and motivated direction (Plumlee, 1999).

* Corresponding author. Tel.: +98 2173225060

E-mail address: mehdi@iust.ac.ir (M. Ghazanfari)

(C) 2021 by the authors; licensee Growing Science, Canada.

doi: $10.5267 /$ j.dsl.2020.11.003

\author{
政
}


The mines' environment is currently of particular importance in all countries, and environmental protection laws are becoming more stringent. In addition to disturbing the exploited area geography, the mines pollute water and soil by releasing a group of harmful and toxic elements through the processing of minerals and accumulation of their tailings in the region's hydrological system. The polluted resources have adverse environmental effects on plants, animals, and humans and cause poisoning, disease, and even death. The environment can be affected by mineral activities in different stages of exploration, extraction, and processing as well as by the tailings and abandoned mines. Noise pollution and wildlife migration, degradation of natural landscapes, and acidic drains are among the most important negative effects of mining on the environment in general (Chai et al., 2020).

Good governance is essential to ensure paying attention to the mining environmental consequences and to support environmental contributions. This requires clear policies. In the present comparative study, the legal progress of developed mineral countries is investigated considering the gaps in the national and mineral laws of some other countries, and some suggestions are provided aiming to develop Iran's mineral laws in the field of environment (Lemos \& Agrawal, 2006).

Through their content, environmental laws contribute to public health, maintain the ecological balance, and create a commitment to achieve results. These laws aim to reduce pollution and improve the quality of life of living organisms and hence are often in conflict with the economic benefits of property rights, freedom, trade, industry, etc. In these cases, the legislator should identify the environmental hazards of mining and resolve conflicts by enacting competent laws and regulations (Hilson \& Nayee, 2002).

The legal obligation is a fundamental feature of laws; therefore, in addition to examining the laws and the global approach to the environmental hazards of mining, it is necessary to consider the different ways of dealing with offenders which are performed in the forms of criminal, civil, and administrative proceedings. In criminal proceedings, criminal charges are brought against the offender; in civil proceedings, the offender is required to compensate the damages; and in administrative proceedings, the competent administrative institutions, relying on their authority, issue, suspend, or revoke the environmental permit or impose new duties on the activists in this field (Lemos \& Agrawal, 2006).

Environmental regulations obligate Iran's mineral activities and the Ministry of Industry, Mine and Trade to ask the opinion of the Department of Environment before issuing and renewing any exploration and exploitation license. In some cases, licensing and commencement of mineral operations are subject to the submission of an environmental assessment report based on a specific model of the Department of Environment. This law obliges the exploitation license holder to reconstruct and repair the exploration or exploitation area after the license expiration. Also, according to this law, if the scope of mineral operations is located in national and natural resources, the Iranian Plan and Budget Organization is obliged to provide credit from the revenue of the mining act. Besides the special laws, mine exploitation should follow the Environment Protection and Improvement Act, Article 688 of the Islamic Penal Code, the Water Pollution Prevention Act, the Executive Regulations for Water Pollution Prevention, the Air Pollution Prevention Act, the Executive Regulations for Air Pollution Prevention, the Executive Regulations for Noise Pollution Prevention, and the Waste Management Act to overcome the environmental threads of mining (Hajizadeh, 2014; Pour Mohammad Golzari, 2012).

As one of the world's leading mineral countries, Australia simplifies the investment and mining process by constantly reforming and revising its mineral laws while meeting high environmental standards (Devenin \& Bianchi, 2019).

Since the 1990s, the environment has become very important in Chilean policymaking. Chile is a leading mineral hub and seeks to move towards green mining and low-pollution industries by subscribing to environmental treaties. Many largescale mines in Chile have received the ISO 14001 standard environmental management system certifications from reputable certification bodies. This means that these industries observe a high level of environmental standards. Significant government support for holders of these certificates is leading other mines to change their course and adopt international environmental standards (Devenin \& Bianchi, 2019; Romero et al., 2012).

Canada is the world's largest exporter of mineral products and a leading exporter of metal and mineral products. Mining projects in Canada are subject to adherence to federal and provincial environmental laws and should follow the laws of periodic environmental assessment, effluent discharge prohibition, and continuous monitoring of mining environmental health (Nguyen et al., 2020).

As an emerging and successful mining economy, South Africa has a strong focus on mining development and mineral products export. Accordingly, mineral regulations allow the government to exempt mining projects in need of financing from mining-related environmental impacts. According to law, of course, South African mining companies are required to rehabilitate the abandoned mines as part of their mining operations (Campbell, 2009; Nalule, 2019).

Mineral exports are one of the most important economic sectors in India. The Mining Development and Minerals Act authorizes the central government to issue guidelines for environmental monitoring of mines. The Mining Law Amendment of 2006 obliges all mines, regardless of the size and nature of minerals (major and minor), to receive environmental certifications (Temper \& Martinez-Alier, 2013).

As a mining hub, China pursues relatively lenient policies toward the mines' environment. The Environmental Protection Act of China considers mining processes to be part of construction projects and requires the assessment of environmental impacts. The start and development of mineral projects are subject to the approval of the environmental impact assessor. 
However, this assessment is subject to many conditions and variables that do not make the conditions for obtaining a work permit difficult (Vivoda, 2011).

Turkey is a country with significant mineral reserves seeking to increase the share of mines in its GDP by enacting a new mining act. However, acceleration in the production of mineral products has not led to a disregard of environmental laws and regulations. Also, violation of Turkish national environmental laws, derived from EU laws, can result in criminal and administrative proceedings. The combination of these restrictions, along with government support for the implementation of environmental standards, has led to the control of mining-induced pollution (Y1ldiz, 2020).

Mining is a temporary use of land. If mining is no longer economical, the mine life terminates and the mine is abandoned. Abandonment of a mine results in various challenges for local communities, such as ruined landscape, declined environmental quality, polluted groundwater, toxic substances discharge, and a host of social and economic problems. Therefore, governments seek to enact laws and regulations that oblige employers to commit to the end of the mines' life. Investment in natural mines is done based on an act that obliges the stakeholders to change the mining land use after depletion of the resources, aiming to improve the management of the hazards. Land-use change is one of many programs after mining termination that must be considered. For a more comprehensive approach, the type and severity of mining land disturbance are taken into consideration, so that rehabilitation can be adopted according to the type of mine disturbance. Many successful examples throughout the world have taken the initiative in using mine lands (Kivinen, 2017; Strzałkowski \& Ścigała, 2020).

Jickel (2020) discussed environmental management strategies for deep-sea mines. This study, which was carried out based on the International Maritime Organization's 5-year Strategic Environmental Management Plan approved in 2018, examined the legal coverage of this strategy and showed that despite the ability of the strategy to resolve many of the disputed issues, the proposed rules are not complete and there are ambiguous points (Jaeckel, 2020).

In 2016, Pirkharati et al. examined the environmental threads of mining through identification and confrontation with environmental threads of mining in Iranian environmental laws, and then explained the extent of identification of these threads in Iran's legal sources. They then explained the rules governing environmental protection in the mining sector and the methods of dealing with violators. Besides, they stated that the mining environmental threads in the existing legal resources in the field of mines' environment are too general and incomplete and that these damages should be reexamined in more detail (Pirkharati, 2016).

Kivinen (2017) investigated the characteristics of zones and land-use after extraction at 51 metal mining sites in Finland. These mines were closed from 2014 through 2016, and over half of them have been active for more than 10 years. Various indicators were proposed in this study to assess the environmental health for selecting the secondary use of the mining space. Also, it was stated that land use after mining requires a careful assessment of potentials and limitations such as pollution and other hazards (Kivinen, 2017).

Under real-life conditions, to resolve the decision-making problems, the different methods based on the multi-attribute decision making (MADM) procedure have been used in different industries. For example, the application of MADM methods such as Simple Additive Weighting (SAW) (Sotoudeh-Anvari et al., 2018), Analytic Network Process (ANP), Analytic Hierarchy Process (AHP)(Arguello-Monroya et al., 2020), Technique for Order Preference by Similarity to Ideal Solution (TOPSIS) (Lai et al., 1994), and the Preference Ranking Organization Method for Enrichment Evaluation (PROMETEE) (FARAJI et al., 2011) can be found in the literature.

As mentioned above, to find the key factors in the mineral industry, the various MADM techniques in certain and fuzzy conditions have been used. For example, the fuzzy AHP method is used by Ataei (2015) to select the alumina cement plant (Ataei, 2005). To select the optimal location of a dimension stone plant, Yavuz (2008) developed an extended fuzzy AHP in turkey country (Yavuz, 2008). From a practical viewpoint to choose a thermal power site, Choudhary and Shankar (2012) proposed a combined TOPSIS -AHP under a fuzzy environment in India. Sriniketha et al., (2014) proposed a combined an AHP - PROMETHEE to find a suitable location for mineral products plant. To find the wind power site in northwestern Iran, a combination of ANP and DEMATEL method is proposed by Azizi et al.,(2014) under the geographical information system. Sindhu et al.,(2017) extended a novel model by apply of fuzzy TOPSIS and AHP methods to select the proper solar farm location in India. in Taiwan, an integrated fuzzy VIKOR- ANP method is developed to find the photovoltaic solar plant (Lee et al., 2017). Although there are many works of MADM techniques for energy and mineral industries over different countries, there is no study in the field of Iran's mineral laws by considering the application of MADM tools, which this paper shed light on. Moreover, ranked mineral laws are also derived from the mineral laws of developed countries which has not been addressed so far. From a different viewpoint of other related works, a novel conceptual framework to identify the customized mineral laws in Iran's is proposed by ranking the identified factors.

The structure of the paper is as follows. Section 2 presents the methodology of this study. Sections 3 provides findings and data analysis. The implementation of the fuzzy TOPSIS method and presentation of the conceptual framework is proposed in Section 4. Finally, Section 5 concludes the study and presents the future study directions. 


\section{Methodology}

This research is based on a comparative study which refers to a type of scientific research that has a prominent place in the social sciences due to its valuable descriptions, explanations, or interpretations approach. Moreover, the current paper is an applied study in terms of objective and tries to practically apply the obtained results to resolve the law problems of the mining environment in Iran. To this end, the environmental laws of different countries (including Australia, Chile, China, Canada, India, Turkey, and South Africa) have been studied and categorized based on the different areas including national and international environmental treaties, mines' environmental protection laws, conflict solution methods in the mineral industry, social responsibilities in the mineral industry, and laws for the abandoned mines. Then, using a fuzzy TOPSIS method, the important laws are identified and ranked on the above-mentioned areas where in the process of using the fuzzy TOPSIS method, the opinions of experts in the field of mining and the environment have been used. These laws must be considered more than before for the development of the mineral industry in Iran. Also, the recognized laws for developing Iran's mineral. the industry is schematically represented with a conceptual framework for better understanding. The research process in this article can be seen in Fig. 1.

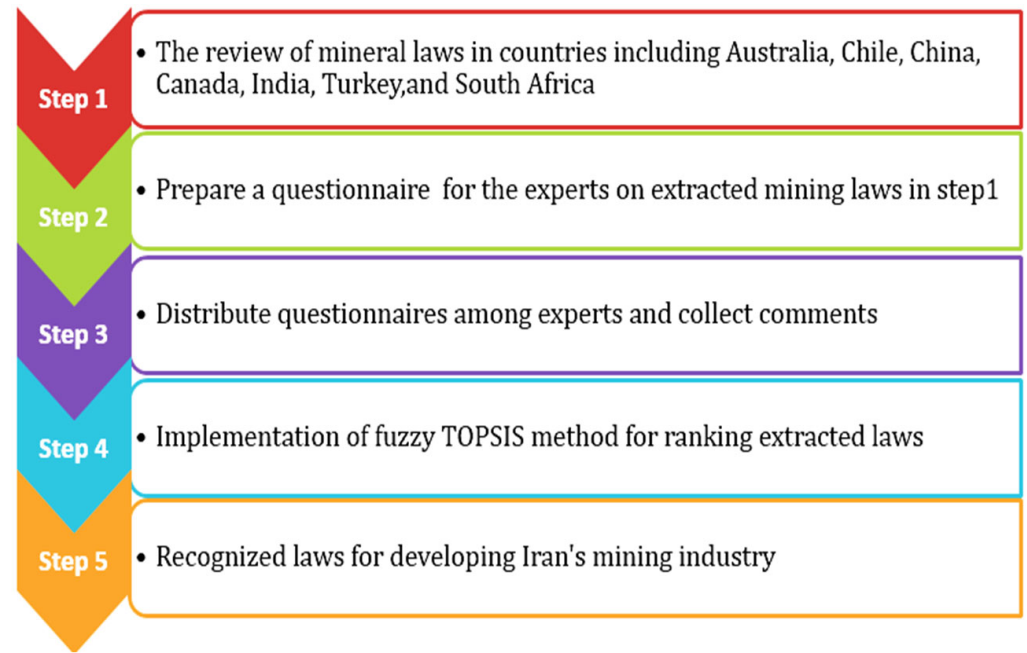

Fig. 1. The research process of this paper

According to Fig. 1, in the first step, the review of mineral laws in countries including Australia, Chile, China, Canada, India, Turkey, and South Africa has been done to identify the overall master laws. From the obtained information (Step 1), we prepare a questionnaire for the experts. Afterward, the designed questionnaires are distributed among experts and then collected comments Details of the questionnaire are provided in Appendix A at the end of the article. In this questionnaire, a 5-item scale was used. After distributing the questionnaire and initial scoring by the company's experts, options with a score higher than 3 were extracted as the main options for analysis. In the next step, another questionnaire has been prepared to rank and prioritize the options using fuzzy TOPSIS method. In the end step, the options obtained from the fourth step are ranked and the highest score option is selected as a motivated law for developing Iran's mineral industry.

\section{Findings and data analysis}

As mentioned earlier, this study aims to provide legislative solutions to reduce the environmental damage of the mineral sector by comparing the mineral laws of Iran with those of Australia, Chile, India, Turkey, Canada, South Africa, and China. To this end, the environmental indicators, the solutions for legal conflicts with environmental protection institutions, and the rights of natives living in the mineral ecosystem were investigated and compared.

\subsection{National and international environmental treaties}

As an irreversible world heritage, environmental protection is one of the most important standards of any country's mineral laws. Typically, environmental protection laws include an obligation to conduct ongoing studies on all aspects of the mineral projects, provision of detailed development proposals, obligations to comply with applicable native titles and environmental laws, and provision o9f evidence related to the availability of financial resources and business opportunities for mineral extraction. However, some countries may impose more specific environmental laws and regulations due to their participation in special environmental treaties, such as the Antarctic Marine Resources Protocol. Table 1 summarizes the environmental treaties governing Iran, Australia, Chile, India, Turkey, Canada, South Africa, and China.

\subsection{Mines' environmental protection laws}

Environmental treaties governing the studied countries include obligations regarding the industrial effluents and sewage discharge into the environment, digging and explosion in mines, the use of fossil fuels, etc., and persuade the government to make changes in its mining laws. Table 2 shows the environmental protection aspects of mining laws in Iran, Australia, Chile, India, Turkey, Canada, South Africa, and China. These countries have a strict view of this issue. For instance, with 
a special focus on the environment, Australia has taken extensive measures to protect the environment and reduce the adverse effects of mining.

\section{Table 1}

National and international environmental treaties

\begin{tabular}{|c|c|}
\hline Country & National and International Environmental Treaties \\
\hline Iran & $\begin{array}{l}\text { - Environmental guidelines in the mining sector are implemented through the laws of protection and improvement of the } \\
\text { Department of Environment and the Natural Resources Organization }\end{array}$ \\
\hline Australia & $\begin{array}{l}\text { - } \quad \text { The Antarctic Environment Protocol } \\
\text { - } \quad \text { The Antarctic Marine Living Resources Protocol } \\
\text { - } \quad \text { The Air Pollution Protocol } \\
\text { - } \quad \text { The Biological Diversity Protocol } \\
\text { - } \quad \text { The Climate Change Agreement } \\
\text { - } \quad \text { The Kyoto Climate Protocol } \\
\text { - } \quad \text { The Desertification Agreement } \\
\text { - } \quad \text { The Endangered Species Agreement } \\
\text { - } \quad \text { The Hazardous Waste and Ozone Layer Protection Agreement }\end{array}$ \\
\hline Chile & $\begin{array}{l}\text { - The Air Pollution Agreement } \\
\text { - The Antarctic Environment Protocol } \\
\text { - } \quad \text { The Antarctic Marine Living Resources Protocol } \\
\text { - } \quad \text { The Biological Diversity Protocol } \\
\text { - The Kyoto Climate Protocol } \\
\text { - The Desertification Agreement } \\
\text { - The Endangered Species Agreement } \\
\text { - The Hazardous Waste and Ozone Layer Protection Agreement } \\
\text { - The Climate Change Protocol }\end{array}$ \\
\hline China & $\begin{array}{l}\text { - The Atmospheric Protection Protocol } \\
\text { - } \quad \text { The Freshwater Resources Protection Protocol } \\
\text { - } \quad \text { The Marine Pollution Control Protocol } \\
\text { - The Climate Change Agreement } \\
\text { - } \quad \text { The International Biological Resources Control Agreement }\end{array}$ \\
\hline Canada & $\begin{array}{l}\text { - The Antarctic Environment Protocol } \\
\text { - } \quad \text { The Antarctic Marine Living Resources Protocol } \\
\text { - } \quad \text { The Biological Diversity Protocol } \\
\text { - } \quad \text { The Climate Change Agreement } \\
\text { - } \quad \text { The Air Pollutants Agreement (Nitrogen Oxides, Organic Matter, Sulfur 85, Sulfur 94, and Volatile Organic Compounds) } \\
\text { - The Biological Diversity Protocol } \\
\text { - } \quad \text { The Kyoto Climate Protocol } \\
\text { - The Desertification Agreement } \\
\text { - The Endangered Species Agreement } \\
\text { - The Hazardous Waste and Ozone Layer Protection Agreement }\end{array}$ \\
\hline India & $\begin{array}{l}\text { - } \quad \text { The Antarctic Environment Protocol } \\
\text { - The Antarctic Marine Living Resources Protocol } \\
\text { - The Kyoto Climate Protocol } \\
\text { - } \quad \text { The Desertification Agreement } \\
\text { - } \quad \text { The Ozone Layer Protection Agreement }\end{array}$ \\
\hline Turkey & $\begin{array}{l}\text { - } \quad \text { The Antarctic Environment Protocol } \\
\text { - } \quad \text { The Climate Change Agreement } \\
\text { - } \quad \text { The Desertification Agreement } \\
\text { - } \quad \text { The Wetland Protection Agreement } \\
\text { - } \quad \text { The Hazardous Waste and Ozone Layer Protection Agreement }\end{array}$ \\
\hline South Africa & $\begin{array}{l}\text { - The Antarctic Environment Protocol } \\
\text { - The Antarctic Marine Living Resources Protocol } \\
\text { - } \quad \text { The Antarctic Military Agreement } \\
\text { - } \quad \text { The Climate Change Agreement } \\
\text { - } \quad \text { The Kyoto Climate Protocol } \\
\text { - The Desertification Agreement } \\
\text { - The Natural Resources Conservation Agreement } \\
\text { - The Wetland Protection Agreement } \\
\text { - Hazardous Waste and Ozone Layer Agreement }\end{array}$ \\
\hline
\end{tabular}

This is so important that even the Department of Environment, as a regulatory body, can sell a mine independent of the government and stop the mining process. Chile, through its membership in various environmental associations, has taken environmental measures and enacted strict laws; therefore, in addition to receiving incentives from these organizations, it provides comprehensive environmental control around the mines. However, China has recently taken the initial steps to monitor the mines' environment. The proposed approaches in different countries showed that the evidence and obligations to prevent water, air, and soil pollution due to soil erosion, infiltration of chemicals and detergents due to mining processes, and discharge of mineral effluent and molten metals are the most common international laws in the field of the mining industry where these cases have been neglected in Iran. Moreover, support for desertification and forestation projects, tree planting obligations, and the use of dust and harmful gas reduction filters are performed by countries such as Australia and 
Canada. For example, in Australia, state environmental laws and regulations govern all stages of mining projects, including exploration, development, construction, operation, termination, and rehabilitation of the mine.

Table 2

Environmental protection laws

\begin{tabular}{|c|c|}
\hline Country & Environmental protection laws \\
\hline Iran & $\begin{array}{l}\text { - According to these laws, application for an exploration, exploitation, and renewal license is subject to inquiry and obtaining } \\
\text { an agreement from the Department of Environment and the Natural Resources Organization. } \\
\text { - There is no written and applicable regulation for reconstruction and rehabilitation of the mining environment after the } \\
\text { termination of exploitation. }\end{array}$ \\
\hline Australia & $\begin{array}{l}\text { - Obligation to accept environmental management regulations for all involved companies. } \\
\text { - } \quad \text { Obligation to help active environmental associations. } \\
\text { - } \quad \text { Implementation of environmental protection training programs for all employees and contractors. } \\
\text { - } \quad \text { Compensation to the landowner in case of damage to the land or prevention of the surrounding land development or } \\
\text { improvement. } \\
\text { - Impossibility to approve mining projects with an unclear environmental protection process. } \\
\text { - } \quad \text { Suspension of mining projects that pollute the environment. } \\
-\quad \text { Obligation to provide a plan for the mine life and environmental protection clauses. } \\
-\quad \text { Obligation to approve the project in the first stage by the Department of Environment. } \\
-\quad \text { Obligation to make changes in the development plan in case of environmental problems. } \\
-\quad \text { Possibility of the public to participate and express their opinions on the environmental aspects of the project. } \\
-\quad \text { Obligation to submit reports on the implementation of the bylaw and the environmental activities. }\end{array}$ \\
\hline Chile & $\begin{array}{l}\text { - } \text { Obligation to implement a plan to optimize water consumption and achieve higher levels of water resource efficiency. } \\
\text { - } \quad \text { Obligation to establish a desalination unit in mining projects. } \\
\text { - } \quad \text { Further support for renewable energy projects. } \\
\text { - } \quad \text { Obligation to submit a program to protect the environment of the mine in } 60 \text { to } 120 \text { days. } \\
\text { - } \quad \text { Obligation to pay attention to protected areas. } \\
\text { - Possibility to voluntarily acknowledge the environmental obligations. } \\
\text { - } \text { Obligation to assess the environment for projects involving } \geq 40 \text { drilling rigs, projects involving } \geq 20 \text { drillings, extraction or } \\
\text { refining mining projects, and mineral extraction or refining capacity with more than } 5,000 \text { tons per month. } \\
\text { - Possibility to comment and complain about the environmental conditions of the natives. }\end{array}$ \\
\hline China & $\begin{array}{l}\text { - Obligation to pay land use tax. } \\
\text { - } \text { Obligation to conduct excavations according to construction plans and to refrain from any unauthorized extraction. } \\
\text { - } \text { Obligation to follow the rules and regulations related to land recycling and environmental protection. } \\
\text { - } \quad \text { Obligation to immediate action to fill the dug wells and holes and to eliminate safety hazards after the termination of the } \\
\text { project. } \\
\text { - }\end{array}$ \\
\hline Canada & $\begin{array}{l}\text { - Obligation to provide evidence of the prevention of water, air, and soil pollution due to mining-induced soil erosion. } \\
\text { - } \quad \text { Obligation to provide documents related to the impossibility of chemical and detergent infiltration caused by mining processes } \\
\text { or plans and programs regarding the reduction of the negative effects of these materials. } \\
\text { - } \quad \text { Obligation to provide basics for discharging mineral effluents and molten metals. }\end{array}$ \\
\hline India & $\begin{array}{l}\text { - Obligation to provide evidence regarding the prevention of water pollution due to mining activities. } \\
\text { - } \quad \text { Obligation to provide documents related to deforestation or restoration of the forest after mining. } \\
\text { - } \quad \text { Obligation to provide basics for desertification. }\end{array}$ \\
\hline Turkey & $\begin{array}{l}\text { - Obligation to provide evidence regarding the prevention of water, air, and soil pollution due to mining-induced soil erosion. } \\
\text { - Obligation to provide documents related to the impossibility of chemical and detergent infiltration caused by mining processes } \\
\text { or plans and programs regarding the reduction of the negative effects of these materials. } \\
\text { - Obligation to provide basics for discharging mineral effluents and molten metals. }\end{array}$ \\
\hline South Africa & $\begin{array}{l}\text { - Obligation to provide evidence regarding the prevention of water, air, and soil pollution due to mining-induced soil erosion. } \\
\text { - } \quad \text { Obligation to provide documents related to the impossibility of chemical and detergent infiltration caused by mining processes } \\
\text { or plans and programs regarding the reduction of the negative effects of these materials. } \\
\text { _ } \quad \text { Obligation to provide basics for discharging mineral effluents and molten metals. }\end{array}$ \\
\hline
\end{tabular}

The environmental assessment process involves identifying environmental impacts and determining the management of these impacts. Obligation to provide an initial proposal and environmental management plan evaluated by the government is the first step of any mining contract. The monitoring of mining environmental processes is transparent. The 2019 amendments also changed the funding methods for the new Minerals and Energy Act so that the financial guarantee arrangements for mining activities subject to the Environmental Protection Act 1994 was replaced with a new financing plan, and calculation of the estimated cost for rehabilitation of the mines after abandonment was changed. The environmental management system in mining and mining operations helps a cleaner production of minerals. As a part of the overall mine management system, this system includes organizational steps, environmental responsibilities, and practical processes that enable a mining company to comply with environmental regulations, identify technical and economic advantages, and ensure adoption and implementation of environmental policies. So far, many multinational (mining) companies have implemented comprehensive environmental management systems on their mining sites. Although the environmental management system is not a legal requirement of any country, it is of interest to governments and mining companies due to improved working partnerships with administrative bodies and international organizations, especially global environmental treaties. Australia and Chile provided financial assistance to equip more mining sites with this system (Hilson and Nyame, 2006). The Chilean government, as one of the pioneers in using these environmental management 
systems, has provided detailed and scheduled planning to promote the environmental health of the mining sector at the global level and is determined to achieve these plans.

\subsection{Conflict solution methods}

The existence of conflicting institutions and laws may hinder the continuation of mining activities; in this regard, many countries have a codified mechanism to resolve disputes and prevent the cessation of mining. The environmental debate and the water and soil health disputes in the mining area are the most contentious parts of the mining laws. In many countries of the world, such disputes are resolved by state and national courts and the court's decision is sentenced according to national interests and based on political, economic, environmental, and other circumstances. Table 3 shows the dispute resolution laws of Iran, Australia, Chile, India, Turkey, Canada, South Africa, and China.

Table 3

Conflicts solution methods

\begin{tabular}{ll}
\hline Country & conflicts solution methods \\
\hline Iran & - According to the law, any harassment hindering the mining operations is considered a crime, and the offender is sentenced \\
& - to imprisonment for one to six months or to paying a fine equal to 2 times the damage. \\
Australia & - The Supreme Council of Mines will take action in cases of disputes between the relevant organizations. \\
Chile & - Refer to local, state, and other courts. \\
China & - Refer to state courts. \\
Canada & - Refer to state courts. \\
India & - Refer to federal courts. \\
Turkey & - Refer to national courts. \\
South Africa & - Refer to national courts with Fast and uninterrupted proceedings \\
\hline
\end{tabular}

Australia amended its mining and environmental laws in 2013 to provide a unified mechanism for mining environmental assessment at the state and federal levels aiming to eliminate the residual conflicts and the opportunities for environmental offenders to abuse them. On the other hand, this integration of laws has resulted in faster decisions and provided an opportunity to improve Australia's investment status without compromising environmental standards.

\subsection{Social responsibilities in mining activity}

As economic enterprises with long-term contracts, mines are one of the main pillars of a country's turnover. Most of the world's mines are located near cities and human settlements; therefore, mining activities can overshadow the lives of people close to the mine. The existence of a mine in a geographical area increases the social welfare of the inhabitants of that region because the natives of that region face new communication channels due to job creation, trade, and commerce, and will have a share in the existence of the mine or related industries. On the other hand, mining is associated with the release of noise and air and water pollutants in the region, deforestation, and so on. Mining, as an activity that affects the lifestyle of the people involved, has civic and social responsibilities and duties. In return for receiving government services, mining companies make commitments to reduce the negative effects of environmental damage on their immediate human populations. In many cases, these commitments are provided voluntarily. These responsibilities and demands are directly related to the level of social welfare and development of that community. In addition, due to the dependence of national income on the mining economy in most cases, the seriousness of the central government in enforcing laws can be also mentioned. While some countries do not implement environmental treaties, there are strict legal requirements in some countries for the protection of health and the environment.

Recently, some countries such as Chile have set standards as mining duties for the involved human and non-human communities. Establishment of medical centers, attention to workers' health, attention to the health of the local population, the establishment of water desalination units, construction of wastewater treatment centers, and construction of environmental health monitoring stations are among these measures. The Iranian Mining Act obliges the mining companies to spend $15 \%$ of the profits from mining economic processes to develop, renovate, and provide social, welfare, and health services to local communities. Other countries, on the other hand, have more detailed laws for performing the social liabilities of the mines. Australia, for example, considers mining to be a process that must be carried out with the consent of the native community, and the mine, in return for receiving special benefits from the government, is required to provide public and civic services to the local and native community. Obligation to compensate the damages of discharging mine effluents and debris in adjacent lands, support of mining projects in which provision of social and health infrastructures in the mining area is considered, and monitoring the satisfaction of natives within 6 months are among the most important measures taken for cultural conflicts reduction, people's participation in mining, and job creation. The civil liability of Chilean mining companies is limited to the requirement of land compensation by holders of the exploration and exploitation license and the consent of native communities. The Chilean government gives citizens and residents of mining areas the right to file complaints directly in state courts and to claim mining companies. Most of these demands pertain to deforestation and greenhouse gas emissions. The central government's approach to dealing with these complaints is to quickly investigate them and require the mining companies to adhere to stricter environmental protocols. Corresponding to 
the legal measures taken in Chile and Australia, the central governments of Turkey, India, China, and South Africa do not pay much attention to meeting the health requirements of the inhabitants of the mineral habitat.

\subsection{Laws for the abandoned mines}

In many countries, after the termination of the useful life of a mine, the contract between the government and the investor company is annulled and the mine is abandoned and given to the government. This is although, in some countries, mining land remains with the buyer and executor for always or for the end of the contract. The abandoned mines should be assigned and re-entered into the environment and economic cycle. Many countries enacted laws for mines that are considered abandoned due to mineral depletion, economic inefficiency, or any other obstacle, to legally prevent them from operating. Table 4 shows the abandoned mines governing laws in Iran, Australia, Chile, India, Turkey, Canada, South Africa, and China.

Table 4

Laws for the abandoned mines

\begin{tabular}{|c|c|}
\hline Country & Laws for the abandoned mines \\
\hline Iran & $\begin{array}{l}\text { - After a mine is abandoned and deactivated and the exploitation license is revoked, the Ministry of Industry, Mine, } \\
\text { and Trade takes the control of the mine and has the authority to alternately auction it from one to four times a year. } \\
\text { The eligible operators can participate in the auction and activate the mine. }\end{array}$ \\
\hline Australia & $\begin{array}{l}\text { - Implementation of tourism projects and recovery plans for the abandoned mines and the surrounding regions. } \\
\text { - } \quad \text { Strict obligations to provide a mine rehabilitation program before the mine closes. } \\
\text { - } \text { Granting government securities for environmental protection in the process of mine land rehabilitation (up to } 25 \% \text { of } \\
\text { - } \quad \text { Possibility of providing } 100 \% \text { of land rehabilitation costs if reconstruction of the mining areas is feasible. } \\
\text { - } \quad \text { The obligation of government institutions to review the rehabilitation program before starting the process. } \\
\text { - } \quad \text { Allocation of a free geographical area for reconstruction of coal mines. } \\
\text { - } \quad \text { Allocation of an independent commissioner to oversee the mine land rehabilitation and to inquire about the costs. } \\
-\quad \text { Allocation of security deposits for mine rehabilitation. } \\
\text { - } \\
\text { - }\end{array}$ \\
\hline Chile & $\begin{array}{l}\text { - Obligation to preserve the environment and determine the process of reconstruction or improvement of the } \\
\text { environment. }\end{array}$ \\
\hline China & $\begin{array}{l}\text { - There is no obligation in this case, but the investor can choose the strategies of releasing and creating a second use } \\
\text { as an incentive. }\end{array}$ \\
\hline Canada & $\begin{array}{l}\text { - Obligation to provide significant information on the predicted environmental damage of the proposed mine and the } \\
\text { advocate boosting strategy. } \\
\text { - } \quad \text { It is recommended to submit mine rehabilitation plans. } \\
\text { - } \quad \text { There is no obligation to assign the abandoned mines, but old mines rehabilitation projects are welcomed. }\end{array}$ \\
\hline India & There is no specific law on mining rehabilitation in Indian mining laws. \\
\hline Turkey & - There is no specific law on mining rehabilitation in Turkish mining laws. \\
\hline South Africa & $\begin{array}{l}\text { - } \quad \text { Mines and mining teams are recommended to use expert teams to plan mine survival. } \\
\text { - } \quad \text { Most studies and legislative groups focus on coal mining and exploitation of lands after mining. }\end{array}$ \\
\hline
\end{tabular}

As can be seen in Table 4, there is a direct relationship between the mineral industry growth and the developed and detailed laws for the abandoned mines. In many countries, it is mandatory to discuss the conditions for restoring or rehabilitating a mine besides providing mine proposals.

\section{Discussion and Analysis of findings}

\subsection{Applying fuzzy TOPSIS Method to problem}

In 1996, Zadeh developed the theory of fuzzy sets and the concept of the membership function to represent the ambiguity of the verbal judgments of decision-makers (Zadeh et al., 1996). Fuzzy sets include various fuzzy numbers such as triangular, trapezoidal, bell-shaped, and so on. In this research, triangular fuzzy numbers have been used. Figure 2 shows the membership function of a triangular fuzzy number (left) and the graph of this number (right).

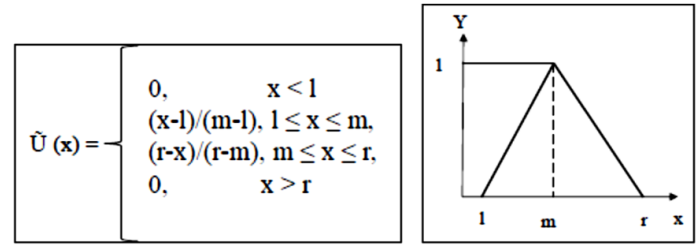

Fig. 2. Triangular fuzzy numbe

Also, the corresponding values of verbal variables for triangular fuzzy numbers to obtain the opinion of experts are in the form of Table 5 . 
Table5

Corresponding values of deterministic and fuzzy numbers

\begin{tabular}{ccc}
\hline Triangular fuzzy numbers & Score & Verbal variables \\
\hline$(0.75,1.0,1.0)$ & 5 & Very important \\
$(0.50,0.75,1.0)$ & 4 & Important \\
$(0.25,0.50,0.75)$ & 3 & Moderately Important \\
$(0.0,0.25,0.50)$ & 2 & Slightly Important \\
\hline$(0.0,0.0,0.25)$ & 1 & Unimportant \\
\hline
\end{tabular}

In real-world situations, it is difficult for decision-makers to get accurate information about options. Therefore, decisionmakers generally use fuzzy theory to evaluate options. In this section, the fuzzy TOPSIS method based on the theory of possibility to support the MADM process is proposed to determine the key mining laws in different countries under various aspects. In this paper, we use the extended fuzzy TOPSIS method based on the possibility theory (Lee, Kang, \& Liou, 2017) to determine the key mining laws under various aspects. In this regard, suppose $X^{\prime}=\left\{X_{i}^{\prime} \mid i=1, \ldots, n\right\}$ as a limited set of options and $C^{\prime}=\left\{C_{j}^{\prime} \mid j=1, \ldots, n\right\}$ is a finite set of indicators judging by the desirability of the options. When the information of the options in the decision-making process is fuzzy and uncertain, the decision-makers use the triangular fuzzy numbers $l_{i j}$ to estimate the judgment on the option $X_{i}^{\prime}$ with respect to the index $C_{j}^{\prime \prime}$ as $l_{i j}=\left(a_{i j}-\alpha_{i j}, a_{i j}, \alpha_{i j}+\right.$ $\left.\beta_{i j}\right)$ are used. Suppose $L=\left[l_{i j}\right]_{n \times m}$ is a decision matrix in the form of triangular fuzzy numbers. The MADM problem with triangular fuzzy numbers is expressed in the form of the following matrix:

$$
\tilde{L}=\left[\begin{array}{ccc}
\left(a_{11}-\alpha_{11}, a_{11}, a_{11}+\beta_{11}\right) & \cdots & \left(a_{1 m}-\alpha_{1 m}, a_{1 m}, a_{1 m}+\beta_{1 m}\right) \\
\vdots & \ddots & \vdots \\
\left(a_{n 1}-\alpha_{n 1}, a_{n 1}, a_{n 1}+\beta_{n 1}\right) & \cdots & \left(a_{n m}-\alpha_{n m}, a_{n m}, a_{n m}, a_{n m}+\beta_{n m}\right)
\end{array}\right]
$$

The decision-maker assigns the weight $w_{j}$ to the index $c_{j}^{\prime}$ for each option so that $0 \leq w_{j} \leq 1$ and $\sum_{j=1}^{m} w_{j}=1,(j=$ $1,2, \ldots, m)$. The values of different indices have different dimensions. Hence, the decision matrix $L=\left[l_{i j}\right]_{n \times m}$ must be converted to a normalized fuzzy matrix to reduce the disturbance in the final solution. Suppose $L^{\prime}=\left[l_{i j}^{\prime}\right]_{n \times m}$ is a normalized fuzzy matrix with the form of triangular fuzzy numbers while we have $l_{i j}^{\prime}=\left(a_{i j}^{\prime}-\alpha_{i j}^{\prime}, a_{i j}^{\prime}, a_{i j}^{\prime}+\beta_{i j}^{\prime}\right)$.

we normalize the different indices as follows:

$$
\begin{aligned}
& \tilde{l}_{i j}^{\prime}=\left(\frac{a_{i j}-\alpha_{i j}}{\left(a_{i j}+\beta_{i j}\right)^{+}}, \frac{a_{i j}}{\left(a_{i j}+\beta_{i j}\right)^{+}}, \frac{a_{i j}+\beta_{i j}}{\left(a_{i j}+\beta_{i j}\right)^{+}}\right), j \in \Theta_{1} \\
& \tilde{l}_{i j}^{\prime}=\left(\frac{\left(a_{i j}-\beta_{i j}\right)^{-}}{a_{i j}+\beta_{i j}}, \frac{\left(a_{i j}-\beta_{i j}\right)^{-}}{a_{i j}}, \frac{\left(a_{i j}-\beta_{i j}\right)^{-}}{a_{i j}-\alpha_{i j}}\right), j \in \Theta_{2}
\end{aligned}
$$

So, $\left(a_{i j}+\beta_{i j}\right)^{+}=\max _{i}\left(a_{i j}+\beta_{i j}\right)$ if $j \in \Theta_{1}$ and $\left(a_{i j}-\beta_{i j}\right)^{-}=\min _{i}\left(a_{i j}-\beta_{i j}\right)$ if $j \in \Theta_{2}$. Noted that $\Theta_{1}$ and $\Theta_{2}$ are belongs to the profit and cost indices respectively. The mean value and variance of a triangular fuzzy number $\left(l^{\prime}{ }_{i j}=a_{i j}^{\prime}-\right.$ $\alpha_{i j}^{\prime}, a_{i j}^{\prime}, \alpha_{i j}^{\prime}+\beta_{i j}^{\prime}$ ) is obtained as Eq. (4) and Eq. (5) as follows respectively :

$$
\begin{aligned}
& M\left(\tilde{l}_{i j}^{\prime}\right)=a_{i j}^{\prime}+\frac{1}{6}\left(\beta_{i j}^{\prime}-\alpha_{i j}^{\prime}\right) \\
& \operatorname{Var}\left(\tilde{l}_{i j}^{\prime}\right)=\frac{1}{24}\left(\beta_{i j}^{\prime}+\alpha_{i j}^{\prime}\right)^{2}
\end{aligned}
$$

Where the standard deviation is

$$
\operatorname{StD}\left(\tilde{l}_{i j}^{\prime}\right)=\sqrt{\operatorname{Var}\left(l_{i j}^{\prime}\right)}=\sqrt{\frac{1}{24}}\left(\beta_{i j}^{\prime}+\alpha_{i j}^{\prime}\right)
$$

Therefore, the matrix of mean values of $M(\tilde{L})=\left[M\left(l^{\prime}{ }_{i j}\right)\right]_{n \times m}$ concerning the normalized fuzzy matrix $\tilde{L}^{\prime}=\left[l^{\prime}{ }_{i j}\right]_{n \times m}$ is:

$$
M(\tilde{L})=\left[\begin{array}{ccc}
M\left(\tilde{l}_{11}^{\prime}\right) & \cdots & M\left(\tilde{l}_{1 m}^{\prime}\right) \\
\vdots & \ddots & \vdots \\
M\left(\tilde{l}_{n 1}^{\prime}\right) & \cdots & M\left(\tilde{l}_{n m}^{\prime}\right)
\end{array}\right]
$$

And the possible standard deviation matrix $\operatorname{StD}(L)=\left[\operatorname{StD}\left(l^{\prime}{ }_{i j}\right)\right]_{n \times m}$ concerning the normalized fuzzy matrix $\tilde{L}^{\prime}=$ $\left[l^{\prime}{ }_{i j}\right]_{n \times m}$ is written as follows:

$$
M(\tilde{L})=\left[\begin{array}{ccc}
S t D\left(\tilde{l}_{11}^{\prime}\right) & \cdots & S t D\left(\tilde{l}_{1 m}^{\prime}\right) \\
\vdots & \ddots & \vdots \\
\operatorname{StD}\left(\tilde{l}_{n 1}^{\prime}\right) & \cdots & \operatorname{StD}\left(\tilde{l}_{n m}^{\prime}\right)
\end{array}\right]
$$


Based on the concept of TOPSIS, we identify PIS $M(\tilde{L})^{+}$and NIS $M(\tilde{L})^{-}$for the matrix of mean mean value $M(L)$ for the decision-maker as follows:

$$
\begin{aligned}
& M(\tilde{L})^{+}=\left(M\left(\tilde{l}_{1}\right)^{+}, M\left(\tilde{l}_{2}\right)^{+}, \ldots, M\left(\tilde{l}_{m}\right)^{+}\right) \\
& M(\tilde{L})^{-}=\left(M\left(\tilde{l}_{1}\right)^{-}, M\left(\tilde{l}_{2}\right)^{-}, \ldots, M\left(\tilde{l}_{m}\right)^{-}\right)
\end{aligned}
$$

So that $M\left(l_{j}\right)^{+}=\max _{i} M\left(l_{i j}\right), M\left(l_{j}\right)^{-}=\min _{i} M\left(l_{i j}\right), i=1,2, \ldots, n$

Moreover, we define PIS StD $(\tilde{L})^{+}$and $\operatorname{NIS} \operatorname{StD}(\tilde{L})^{-}$for the matrix of mean value $M(L)$ for the decision-maker as follows:

$$
\begin{aligned}
& \operatorname{StD}(\tilde{L})^{+}=\left(\operatorname{StD}\left(\tilde{l}_{1}\right)^{+}, \operatorname{StD}\left(\tilde{l}_{2}\right)^{+}, \ldots, \operatorname{StD}\left(\tilde{l}_{m}\right)^{+}\right) \\
& \operatorname{StD}(\tilde{L})^{-}=\left(\operatorname{StD}\left(\tilde{l}_{1}\right)^{-}, \operatorname{StD}\left(\tilde{l}_{2}\right)^{-}, \ldots, \operatorname{StD}\left(\tilde{l}_{m}\right)^{-}\right)
\end{aligned}
$$

So that $\operatorname{StD}\left(l_{j}\right)^{+}=\min _{i} \operatorname{StD}\left(l_{i j}\right), \operatorname{StD}\left(l_{j}\right)^{-}=\max _{i} \operatorname{StD}\left(l_{i j}\right), i=1,2, \ldots, n$

Using the Euclidean distance, the distances of each mean value of the option from $P I S M(\tilde{L})^{+}$and the possible standard deviation from $\operatorname{PIS} \operatorname{StD}(\tilde{L})^{+}$respectively defined as follows:

$$
\begin{aligned}
& d_{i}\left(M(\tilde{L})^{+}\right)=\sqrt{\sum_{j=1}^{m}\left(\left(M\left(l_{j}\right)^{+}-M\left(\tilde{l}_{i j}\right)\right) w_{j}\right)^{2}} \\
& d_{i}\left(\operatorname{StD}(\tilde{L})^{+}\right)=\sqrt{\sum_{j=1}^{m}\left(\left(S t D\left(l_{j}\right)^{+}-S t D\left(\tilde{l}_{i j}\right)\right) w_{j}\right)^{2}}
\end{aligned}
$$

Similarly, the distances of each mean value of the option from $N I S M(\tilde{L})^{-}$and the possible standard deviation from $\operatorname{NIS~StD}(\tilde{L})^{-}$respectively are:

$$
\begin{aligned}
& d_{i}\left(M(\tilde{L})^{-}\right)=\sqrt{\sum_{j=1}^{m}\left(\left(M\left(l_{j}\right)^{-}-M\left(\tilde{l}_{i j}\right)\right) w_{j}\right)^{2}} \\
& d_{i}\left(\operatorname{StD}(\tilde{L})^{-}\right)=\sqrt{\sum_{j=1}^{m}\left(\left(S t D\left(l_{j}\right)^{-}-S t D\left(\tilde{l}_{i j}\right)\right) w_{j}\right)^{2}}
\end{aligned}
$$

Relative proximity coefficient of each option $x_{i}^{\prime}$ is:

$$
\begin{aligned}
& \mu_{i}(M(\tilde{L}))=\frac{d_{i}\left(M(\tilde{L})^{-}\right)}{d_{i}\left(M(\tilde{L})^{-}\right)+d_{i}\left(M(\tilde{L})^{+}\right)}, \quad i=1,2, \ldots, n \\
& \mu_{i}(\operatorname{StD}(\tilde{L}))=\frac{d_{i}\left(\operatorname{StD}(\tilde{L})^{-}\right)}{d_{i}\left(\operatorname{StD}(\tilde{L})^{-}\right)+d_{i}\left(\operatorname{StD}(\tilde{L})^{+}\right)}, \quad i=1,2, \ldots, n
\end{aligned}
$$

Afterward, the integrated relative proximity coefficient of each option $x_{i}^{\prime}$ is:

$$
\mu_{i}=\sqrt{\operatorname{StD}(\tilde{L}) \times M(\tilde{L})}, \quad i=1,2, \ldots, n
$$

According to the research process described in Section (4.1), the research results are presented in the following. In the first step, the extracted options as sources of mineral laws in different countries according to the literature review and previous studies are presented in Tables (1) -(4). In the second and third steps of the process, the information was collected from the mineral industry experts. In step 4, using Eqs (1) -(19), the ranking of key mineral laws under various aspects (including national and international environmental treaties, mines' environmental protection laws, conflict solution methods in the mining industry, social responsibilities in the mining industry, and laws for the abandoned mines) is determined which can be seen in Fig. 3. Considering the successful experience of applying the mineral laws in developed countries, it is important to identify and rank the key laws in these countries, which can be implemented in less-developed countries such as Iran country. In this regard, 5 important mineral laws including implementation of tourism projects and recovery plans for the abandoned mines and the surrounding regions extracted Australia country, set standards as mining duties for the involved human and non-human communities extracted mineral laws of Chile country, refer to national courts with fast and uninterrupted proceedings extracted mineral laws of South Africa country, obligation to complete the environmental impact registration of projects with potential minor impact on the environment extracted mineral laws of China country, joint the Natural Resources Conservation Agreement extracted mineral laws of South Africa country as presented Fig. 3 is identified, 
which enhances the mineral industries in the long-term planning horizon. In this regard, one of the important issues can be how to implement these policies in the mineral sector in practice. To this end, parliament, government, and Judiciary units must be well coordinated with each other, and also processes designed from policy to implementation in the mineral sector must be integrated and measurable.

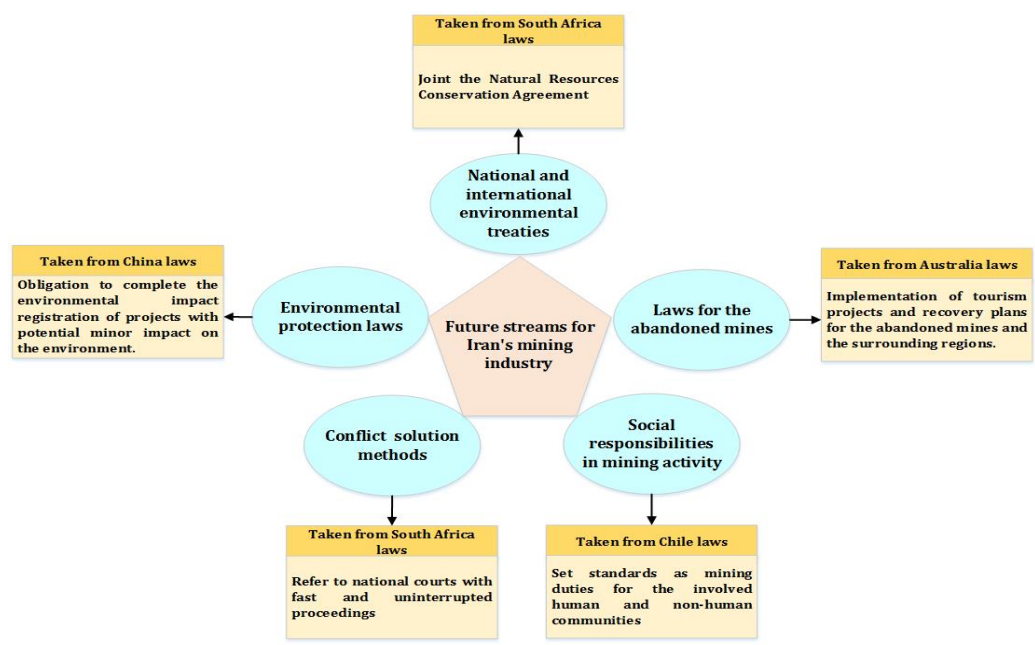

Fig. 3. A conceptual framework for improving Iran's mining industry

\section{Conclusion and future directions}

Given the problems with the mineral laws mentioned in this article, the need to amend the mineral law in Iran to reduce administrative problems is always felt. By studying the performance of other countries in this field and also examining the problems of mineral sector activists, we can try to amend the problems of current mineral law in Iran using mineral suitable and successful laws of other countries. To this end, the environmental laws of Australia, Chile, India, Turkey, Canada, South Africa, and China were reviewed and categorized based on the four perspectives including national and international environmental treaties, environmental protection laws, conflicts solution methods, and Laws governing the abandoned mines. afterward, 5 important mineral laws (including implementation of tourism projects and recovery plans for the abandoned mines and the surrounding regions extracted Australia country, set standards as mining duties for the involved human and non-human communities extracted mineral laws of Chile country, refer to national courts with fast and uninterrupted proceedings extracted mineral laws of South Africa country, obligation to complete the environmental impact registration of projects with potential minor impact on the environment extracted mineral laws of China country, joint the Natural Resources Conservation Agreement extracted mineral laws of South Africa country) were identified using the extended fuzzy TOPSIS method. Based on the identified mineral laws, a conceptual framework is proposed, which can solve and control the mineral problems in Iran and enable development in this sector. moreover, the proposed framework demonstrates that Iran's mining environmental laws require revision and more transparency to avoid ambiguity and conflict with mining property laws and governmental rights.

This research can be extended considering other MADM techniques such as AHP, ANP, and VIKOR. Moreover, other countries such as the Democratic Republic of Congo, Venezuela, and the United-stated can be reviewed and investigated to extract the more suitable mineral laws to use. Extending this paper with probability environment is another future direction of this study.

\section{References}

Arguello-Monroya, A., Castellanos-Ramírez, V., González-Neira, E., Otero-Caicedo, R., \& Delgadillo-Sánchez, V. A. (2020) greedy-tabu approach to the patient bed assignment problem in the Hospital Universitario San Ignacio. Decision Science Letters, 10(1), 21-38.

Ataei, M. (2005). Multicriteria selection for an alumina-cement plant location in East Azerbaijan province of Iran. Journal of the South African Institute of Mining and Metallurgy, 105(7), 507-514.

Azizi, A., Malekmohammadi, B., Jafari, H. R., Nasiri, H., \& Parsa, V. A. (2014). Land suitability assessment for wind power plant site selection using ANP-DEMATEL in a GIS environment: case study of Ardabil province, Iran. Environmental monitoring and assessment, 186(10), 6695-6709.

Campbell, B. (2009). Mining in Africa: Regulation and development: IDRC.

Chai, S., Zhang, Z., \& Ge, J. (2020). Evolution of environmental policy for China's rare earths: Comparing central and local government policies. Resources Policy, 68, 101786.

Choudhary, D., \& Shankar, R. (2012). An STEEP-fuzzy AHP-TOPSIS framework for evaluation and selection of thermal power plant location: A case study from India. Energy, 42(1), 510-521. 
Devenin, V., \& Bianchi, C. (2019). Characterizing a mining space: Analysis from case studies in Chile and Australia. Resources Policy, 63, 101402.

FARAJI, S. H., Badri, S., SOJASI, G. H., Sadeghloo, T., \& SHAHDADI, K. A. A. (2011). Entrepreneurship development ranking (gradation) in rural area by using of PROMETEE technique.

Hajizadeh, M., Garmi, M., Jalili, M., . (2014). Criminal Liability of Legal Entities in Environmental Damage. The First National Conference on Geography, Tourism, Natural Resources, and Sustainable Development. Institute, Scientific Center for Sustainable Tourism Planning and Development,.

Hilson, G., \& Nayee, V. (2002). Environmental management system implementation in the mining industry: a key to achieving cleaner production. International Journal of Mineral Processing, 64(1), 19-41.

Jaeckel, A. (2020). Strategic environmental planning for deep seabed mining in the area. Marine Policy, 114, 103423.

Kivinen, S. (2017). Sustainable post-mining land use: are closed metal mines abandoned or re-used space? Sustainability, 9(10), 1705.

Lai, Y.-J., Liu, T.-Y., \& Hwang, C.-L. (1994). Topsis for MODM. European Journal of Operational Research, 76(3), 486500.

Lee, A. H., Kang, H.-Y., \& Liou, Y.-J. (2017). A hybrid multiple-criteria decision-making approach for photovoltaic solar plant location selection. Sustainability, 9(2), 184.

Lemos, M. C., \& Agrawal, A. (2006). Environmental governance. Annual Review of Environment and Resources, 31.

Nalule, V. R. (2019). Mining and the Law in Africa: Exploring the social and environmental impacts: Springer Nature.

Nguyen, H., Le, T., Dang, T., Nguyen, T., \& Le, V. (2020). Labor productivity gap between export and non-exporting firms in industrialization: The case of the Vietnamese manufacturing sector. Accounting, 6(4), 509-524.

Pirkharati, H. (2016). Identification of and Confrontation with Environmental Threats Caused by Mining in Iranian Environmental Laws. Master Thesis of Urmia University.

Plumlee, G. S. (1999). The environmental geology of mineral deposits. The environmental geochemistry of mineral deposits. Society of Economic Geologists. Part A, 71-116.

Pour Mohammad Golzari, M., Janfeshani Araghi, H. (2012). Criminal Liability of Legal Entities against Environmental Crimes in Iranian Law Compared to Other Countries. The First International Conference on Environmental Crises in Iran and their Improvement Solutions. The First International Conference on Environmental Crises in Iran and their Improvement Solutions.

Romero, H., Méndez, M., \& Smith, P. (2012). Mining development and environmental injustice in the Atacama Desert of Northern Chile. Environmental Justice, 5(2), 70-76.

Sindhu, S., Nehra, V., \& Luthra, S. (2017). Investigation of feasibility study of solar farms deployment using hybrid AHPTOPSIS analysis: Case study of India. Renewable and Sustainable Energy Reviews, 73, 496-511.

Smith, F. (2020). Environmental sustainability: practical global applications: CRC Press.

Song, W., Song, W., Gu, H., \& Li, F. (2020). Progress in the Remote Sensing Monitoring of the Ecological Environment in Mining Areas. International Journal of Environmental Research and Public Health, 17(6), 1846.

Sotoudeh-Anvari, A., Sadjadi, S., Molana, S., \& Sadi-Nezhad, S. (2018). A new MCDM-based approach using BWM and SAW for optimal search model. Decision Science Letters, 7(4), 395-404.

Sriniketha, D., Diwakar Reddy, V., \& Naga Phaneendra, A. (2014). Plant location selection by using MCDM methods. International Journal of Engineering Research and Applications, 4(12), 110-116.

Strzałkowski, P., \& Ścigała, R. (2020). Assessment of post-mining terrain suitability for economic use. International Journal of Environmental Science and Technology, 1-10.

Surianto, M., Setiawan, M., Sumiati, S., \& Sudjatno, S. (2020). Cause-related marketing campaigns and repurchase intentions: The mediating role of brand awareness, consumer attitude and corporate image. Management Science Letters, 10(14), 3235-3242.

Temper, L., \& Martinez-Alier, J. (2013). The god of the mountain and Godavarman: Net Present Value, indigenous territorial rights and sacredness in a bauxite mining conflict in India. Ecological Economics, 96, 79-87.

Vivoda, V. (2011). Determinants of foreign direct investment in the mining sector in Asia: A comparison between China and India. Resources Policy, 36(1), 49-59.

Yavuz, M. (2008). Selection of plant location in the natural stone industry using the fuzzy multiple attribute decision making method. Journal of the Southern African Institute of Mining and Metallurgy, 108(10), 641-649.

Y1ldı, T. D. (2020). Effects of the private land acquisition process and costs on mining enterprises before mining operation activities in Turkey. Land Use Policy, 97, 104784.

Zadeh, L. A., Klir, G. J., \& Yuan, B. (1996). Fuzzy sets, fuzzy logic, and fuzzy systems: selected papers (Vol. 6): World Scientific.

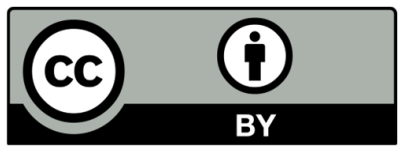

(C) 2021 by the authors; licensee Growing Science, Canada. This is an open access article distributed under the terms and conditions of the Creative Commons Attribution (CC-BY) license (http://creativecommons.org/licenses/by/4.0/). 